\title{
Novel technique for hill climbing search to reach maximum power point tracking
}

\author{
Ahmed Samir Badawi ${ }^{1}$, Nurul Fadzlin Hasbullah², Siti Hajar Yusoff ${ }^{3}$, Aisha H Hashim ${ }^{4}$, \\ Alhareth Zyoud ${ }^{5}$ \\ 1,2,3,4 Department of Electrical and Computer Engineering, International Islamic University Malaysia, Malaysia \\ ${ }^{5}$ Department of Electrical and Computer Engineering, Birzeit University, PO Box 14, Birzeit, West Bank, Palestine
}

\begin{tabular}{l} 
Article Info \\
\hline Article history: \\
Received Feb 9, 2020 \\
Revised Apr 14, 2020 \\
Accepted May 9, 2020 \\
\hline Keywords: \\
Hill climbing search \\
Maximum power point tracking \\
Wind energy conversion system \\
Wind turbine
\end{tabular}

\begin{abstract}
In this paper, a new technique has been proposed to solve the trade off common problem in hill climbing search algorithm (HCS) to reach maximum power point tracking (MPPT). The main aim of the new technique is to increase the power efficiency for the wind energy conversion system (WECS). The proposed technique has been combined the three-mode algorithm to be simpler. The novel algorithm is increasing the ability to reach the MPPT without delay. The novel algorithm shows fast tracking capability and enhanced stability under change wind speed conditions.
\end{abstract}

This is an open access article under the CC BY-SA license.

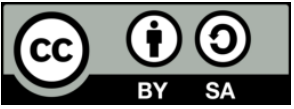

\section{Corresponding Author:}

Nurul Fadzlin Hasbullah,

Departement of Electrical and Computer Engineering,

International Islamic University Malaysia,

53100 Gombak, Malaysia.

Email: nurulfadzlinhasbullah@gmail.com

\section{INTRODUCTION}

Maximum power point tracking (MPPT) is of the paramount importance in renewable energy regimes for not only to maximize the system's power efficiency, but also to reduce the return period of the installation expenses cost and good power quality and reliable. In this research, the targeted algorithm is hill climbing search (HCS) under the direct power control (DPC), to increase the output power direct through the duty cycle, and to reach maximum peak point on the DC link. HCS method is considered an example of a perturb and observe $(\mathrm{P} \& \mathrm{O})$ technique [1-4]. There are many features for HCS algorithm; it's considered the simplest method, not require any prior knowledge about wind energy conversion system (WECS) or aerodynamics characteristics. It can be applied to any WECS, suitable for small scale wind turbine (WT) and this type of algorithm can bring the operating point toward power coefficient $(\mathrm{Cp})$ by increasing or decreasing the perturbing [5-9].

There are two main types according to the maximization of captured power. The first type is DPC concern in the power output direct in the WECS. Whereas, the second type is indirect power control (IDC), increased the mechanical power in the WECS as shown in Figure 1.

The input of HCS is considered electric power since it can be simply measured using the converter [10-15]. However, it is in reality the turbine power that must be applied for the control strategy to reach to the peak point. Since no data for the wind turbine WT is needed, it is ensured that the WT will reach to its real maximum power point, even through variations of external blade characteristics or factors [16]. 
In Figure 2, HCS algorithm concept, perturbing the control variable until reach maximum peak point. In spite of these special properties that lead HCS algorithm to be the best option for MPPT control in any WECS. However, in fact, it is only appropriate in the slow changing wind speed conditions. Therefore, HCS traditional algorithm has two major problems; trade-off between speed and efficiency, and the second is the perturbation step size [8, 17-19].

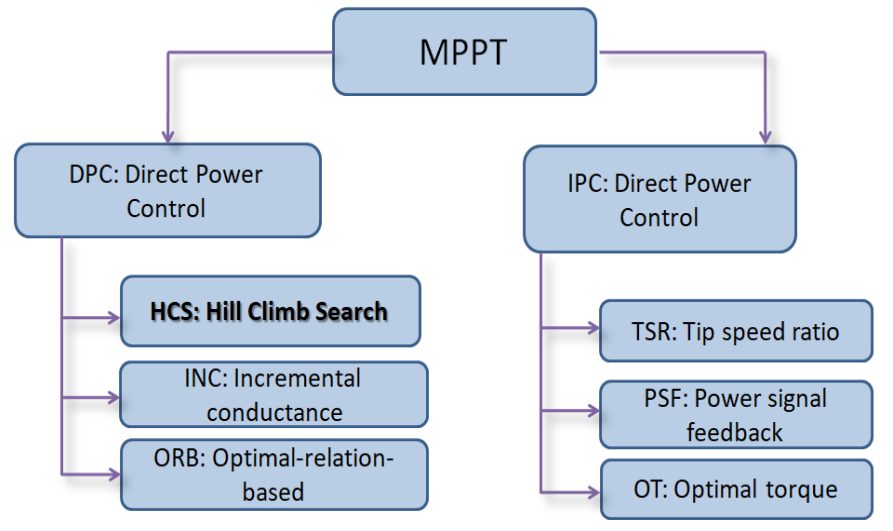

Figure 1. Classification of MPPT according the maximization of total captured power

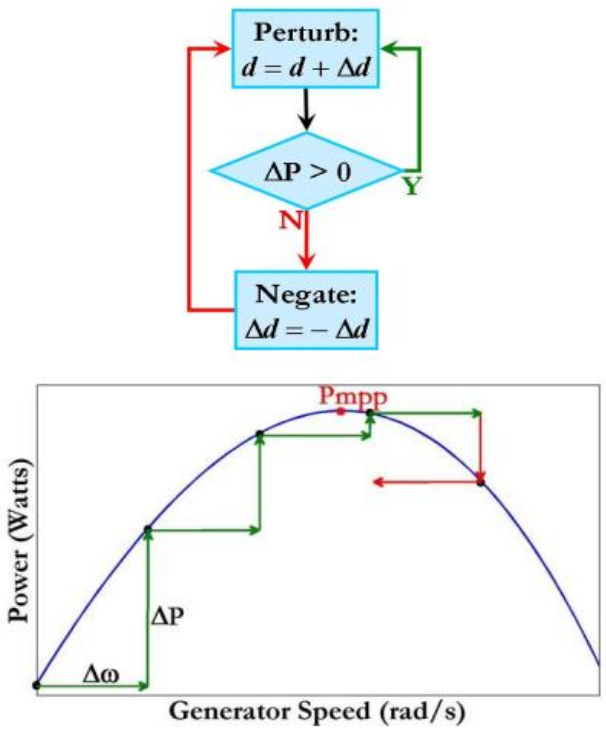

Figure 2. The main principle of HCS algorithm, Perturbing the control variable until reach maximum peak point

The main objective of this research is to increase the power efficiency for the WECS. The power efficiency for the WECS can be increased using HCS algorithms to decrease the number of iterations to reach the decision for the MPPT, and tuning parameters for the DC link [20]. Palestine is suffering from environment pollution problems, especially Gaza strip region after the last three wars. In addition, the siege imposed on Gaza strip, and the continued interruption of electric power as well as fuel make the need to an alternative source of energy instead of traditional sources. The Gaza Strip has an increasing demand for electrical power with an increasing shortage of power supplies [21-23]. Figure 3 shows Palestine map which there is a deficit in electricity due to siege and prevailing war-torn conditions. Moreover, electricity generation is not feasible to satisfy the demand.

Many researchers are actively proposing algorithms to extract maximum power point out of WT. However, this solution cannot be adaptable for Palestine due to the different wind condition compared with other places [9]. There are many techniques under MPPT. However, among these, three mode HSC algorithm is more feasible to be implemented in Palestine, this is due to reduction of step fluctuations and suitable for micro grid system, but the three mode HCS algorithm cannot reach maximum powerpoint due to convergence speed delay, wrong tracking direction, trade-off between speed for detection the maximum power point and accuracy of tracking technique [26-28].

Figure 4 shows the three mode HCS algorithm [17]. Many systems have a master controller that knows in which mode the controller is operating, relaying on wind speed, differences in wind speed, in this approach, the controller can response differently on smaller or larger wind speed changes or it can keep the rotor speed steady as long as the wind speed changes does not exceed any dead band limit. The probability for adaptive HCS algorithm arises, which are first operating in a learning mode to determine all the important parameters in function of a certain wind pattern [29].

Figure 5 illustrates the mechanism for the three mode HCS algorithms to reach the MPPT. Basically, it's relay on the comparison between the pervious state and the next state. Thus, it spends long time to reach the maximum peak point. Moreover, the algorithm is very complicated due to the iteration process to reach MPPT $[8,17]$. 

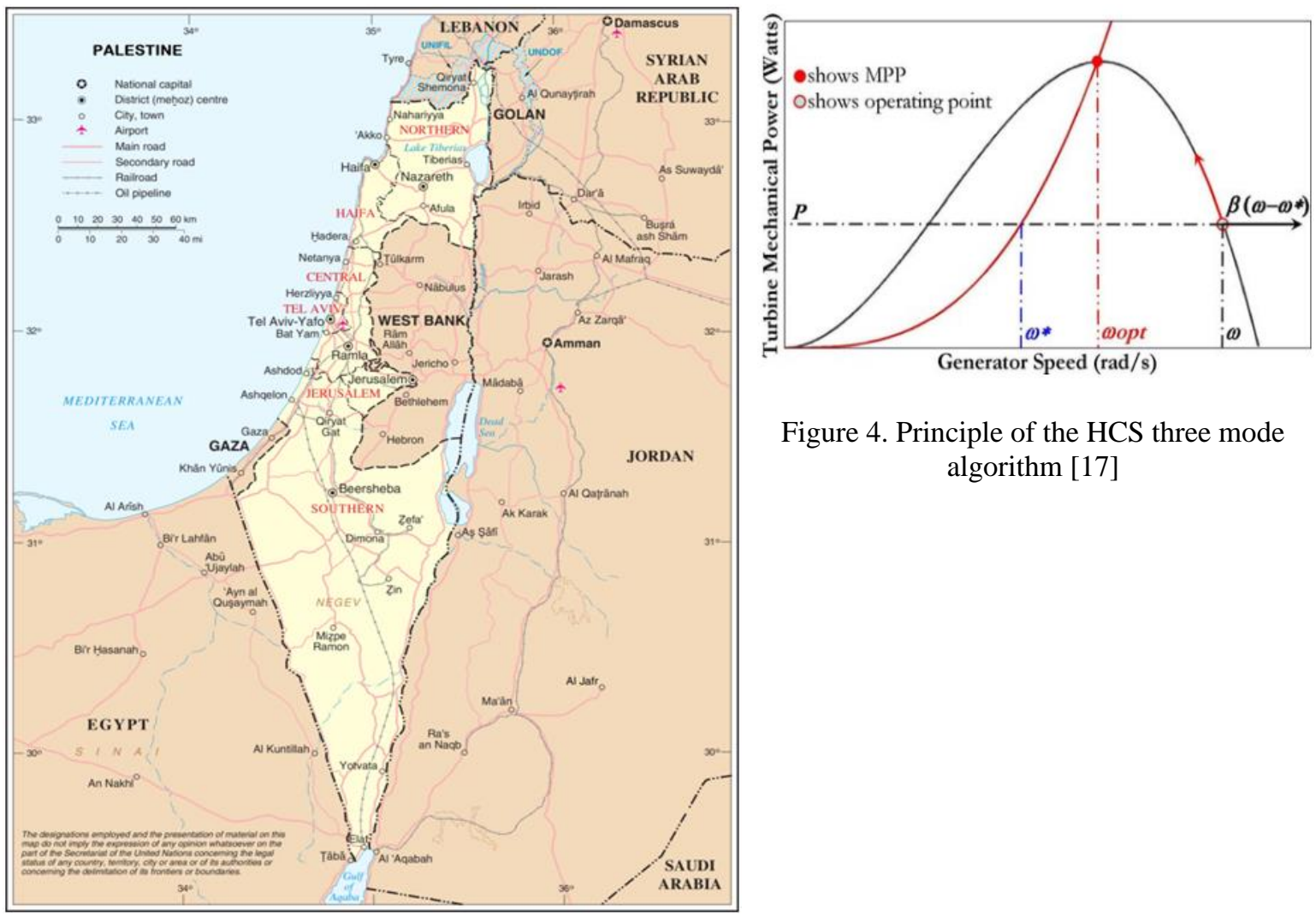

Figure 4. Principle of the HCS three mode algorithm [17]

Figure 3. Palestine map [24, 25]

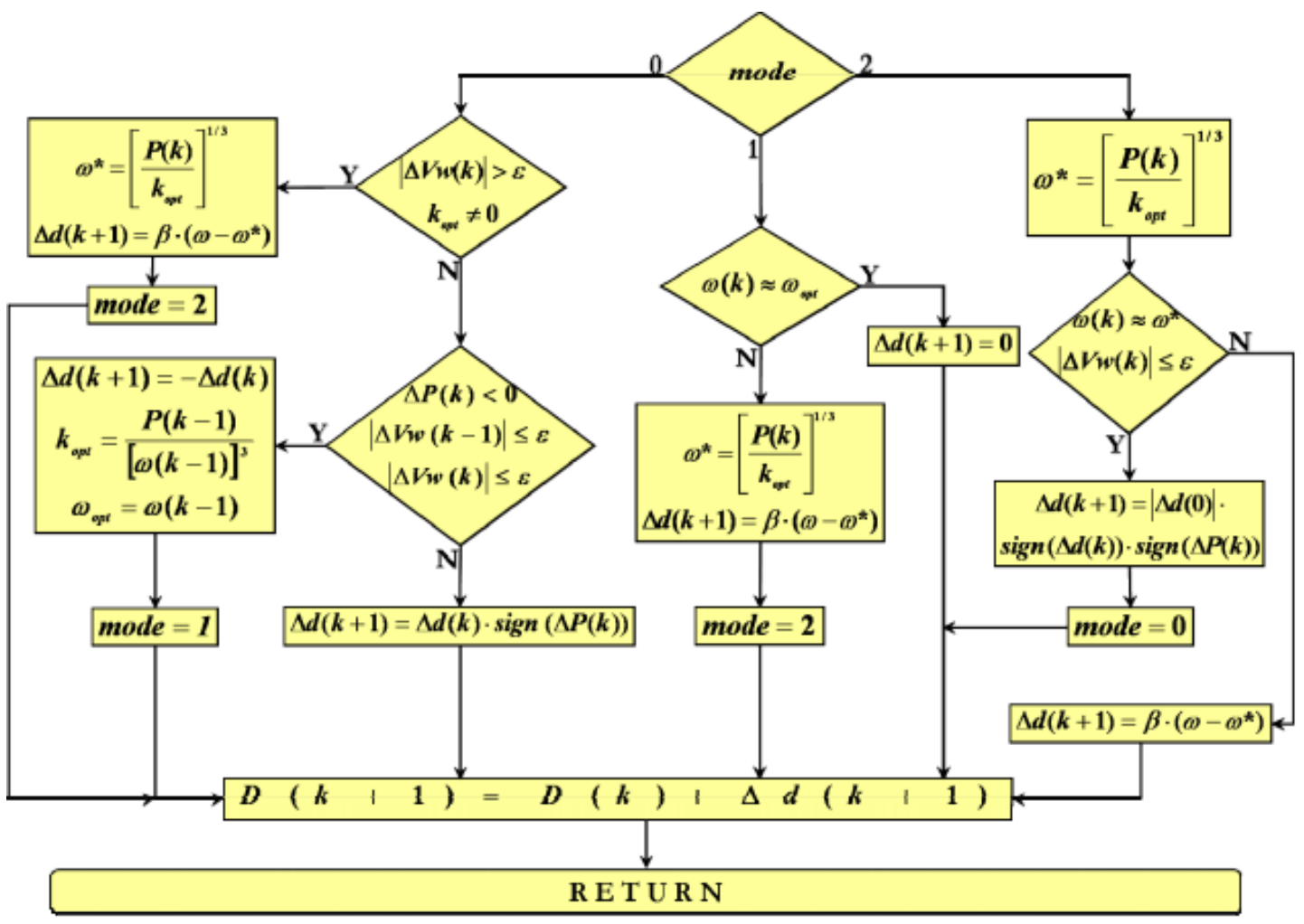

Figure 5. Flowchart of three mode HCS algorithm MPPT [17] 


\section{WIND SPEED AND MPPT RELATION}

The power output from a WT relies on the rotor swept area, density of air and velocity of the wind. The common power equation for a WT is given by (14) based on case of constant acceleration [30]. The velocity $v$ is equal to the work done $\mathrm{W}$, and the kinetic energy of an object having mass $\mathrm{m}$, the distance $\mathrm{s}$ under a force $\mathrm{F}$, as the following.

$$
E=W=F S
$$

Applying Newton's Law:

$$
F=m a
$$

Hence,

$$
E=\operatorname{mas}
$$

Using equation (3) of motion:

$$
v^{2}=u^{2}+2 a s
$$

We can get:

$$
a=\frac{\left(v^{2}-u^{2}\right)}{2 s}
$$

The object initial velocity is 0 , i.e. $\mathrm{u}=0$, then:

$$
a=\frac{v^{2}}{2 s}
$$

Substituting it in (3), the kinetic energy of a mass is:

$$
E=0.5 m v^{2}
$$

The wind power is given by the rate of change of energy as the following equation:

$$
P=\frac{d E}{d t}=\frac{1}{2} v^{2} \frac{d m}{d t}
$$

As mass flow rate is given by:

$$
\frac{d m}{d t}=\rho A \frac{d x}{d t}
$$

The rate of change of distance is given by:

$$
\frac{d x}{d t}=v
$$

Then

$$
\frac{d m}{d t}=\rho A v
$$

E=Kinetic energy $(J), \rho=$ Density $\left(\mathrm{kg} / \mathrm{m}^{3}\right), \mathrm{m}=$ Mass $(\mathrm{kg}), A=$ Swept Area $\left(\mathrm{m}^{2}\right), \mathrm{v}=$ Wind Speed $(\mathrm{m} / \mathrm{s})$, $\mathrm{Cp}=$ Power coefficient, $\mathrm{P}=$ Power $(\mathrm{W}), \mathrm{dt} / \mathrm{dm}=$ Mass flow rate $(\mathrm{kg} / \mathrm{s}), \mathrm{r}=\operatorname{Radius}(\mathrm{m}), \mathrm{x}=\operatorname{distance}(\mathrm{m}), \mathrm{t}=\mathrm{time}(\mathrm{s})$, $\mathrm{dt} / \mathrm{dE}=$ Energy flow rate $(\mathrm{J} / \mathrm{s})$.

Therefore, from (8), the power can be represented as the following equation:

$$
P=0.5 \rho A v^{3}
$$


The captured power from the wind can be expressed as the following equation:

$$
\text { Pavail }=0.5 \rho A v^{3} C_{P}
$$

The swept area of the wind turbine can be computed from the length of the wind turbine blades using the equation for the swept area of a circle $A=\pi r$

$$
P=0.5 c_{P(\lambda, \beta)} \rho \pi R^{2} V_{w}^{3}
$$

Where, $c p=$ power coefficient, $V w=$ Wind velocity, $\rho a=$ density of air, and and $\mathrm{R}=$ rotor radius. The power coefficient $(c p)$ for the WT is the maximum power that could be captured of the total available in the wind, $c p$ is a function of blade pitch angle $(\beta)$ and blade tip speed ratio $(\lambda)$. Theoretically, a wind turbine can extract maximum $59.3 \%$ from the total power of wind (Betz's limit)[9]. Betz limit identified as a WT can only convert $59.3 \%$ maximum of the total available energy in the wind into kinetic energy. Practically a WT can extracts around $40 \%$ of the power in the wind in the ideal WT power [31].

For small scale WT, $\beta$ angle between the reference line and chord of the blade on the rotor hub, normally zero or kept constant. Consequently, for a constant pitch angle, power coefficient is only a function of tip speed ratio. The tip speed ratio $\lambda$ is a ratio between the wind speed $(\mathrm{V} w)$ and speed of the blade tip (Vtip) as shown in (15) [31].

$$
\lambda=\frac{\mathrm{v}_{\mathrm{tip}}}{\mathrm{V}_{\mathrm{w}}}=\frac{\omega_{\mathrm{r}}}{\mathrm{v}_{\mathrm{w}}}
$$

where, $\omega r$ is the turbine angular speed. The wind turbine dynamic equation is given by (16) [31].

$$
\frac{d_{\omega_{r}}}{d t}=\frac{T_{m}-T_{L}-F_{\omega_{r}}}{J}
$$

where, $\mathrm{F}$ is the viscous friction coefficient, $\mathrm{J}$ is the system inertia, TL is the torque due to load, Tm is the torque given by the turbine. The power coefficient $C p(\lambda, \beta)$ can be determined for WT by (17).

$$
c_{p}(\lambda, \beta)=c_{1}\left(\frac{c_{2}}{\lambda_{i}}-c_{3} \beta-c_{4}\right) e^{\frac{-c_{5}}{\lambda_{i}}}+c_{6} \lambda
$$

where, $\lambda i$ is a variable which is a function of $\lambda, \beta$ is defined as in (18),

$$
\frac{1}{\lambda_{i}}=\frac{1}{\lambda+0.08 \beta}-\frac{0.035}{\beta^{3}+1}
$$

Substituting (16) through to (17), the coefficients from c1 to c6 are: $\mathrm{c} 3=0.4, \mathrm{c} 1=0.5176, \mathrm{c} 4=5, \mathrm{c} 2$

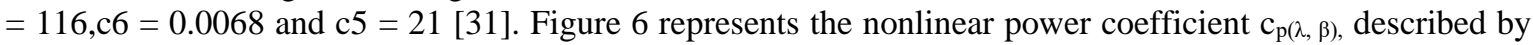
(17), according to the tip speed ratio $\lambda$ for various values of $\beta$ pitch angle [31].

Mean wind speed play important role in the wind power generation process due to the cubic proportional relation between power and mean wind speed. Average wind speed reflects to the rotor speed. Therefore, total output power is proportional with rotor speed as shown in (14). Figure 7 presents that rotor speed versus output power for each wind speed, there is a maximum output amount of power that the WT could extract if WT operated at the rated rotor speed $\left(\omega_{\text {opt }}\right)$ or to the optimum rotor speed value $\omega_{\text {opt }}$ can reached at the optimum $\left(\lambda_{\text {opt }}\right)$. in order to collect maximum possible power from the WT. WT must be turned on at optimal TSR $\lambda_{\text {opt }}$. This case of operation is possible by controlling the rotational speed of the WT that it always turns on at the optimum or rated speed.

$$
P_{\text {max }}=K_{\text {opt }} \omega_{\text {ropt }}^{3}
$$

Where, $\mathrm{K}_{\mathrm{opt}}$ is an optimum wind written by (20).

$$
K_{o p t}=\frac{0.5 \pi \rho C_{p \max R^{5}}}{\lambda_{o p t}^{3}}
$$




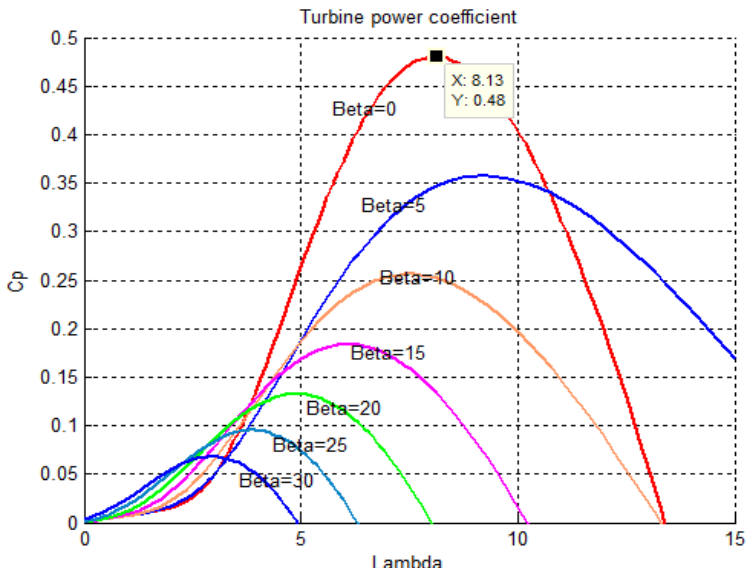

Figure 6. Power coefficient $c_{p}(\lambda, \beta)$

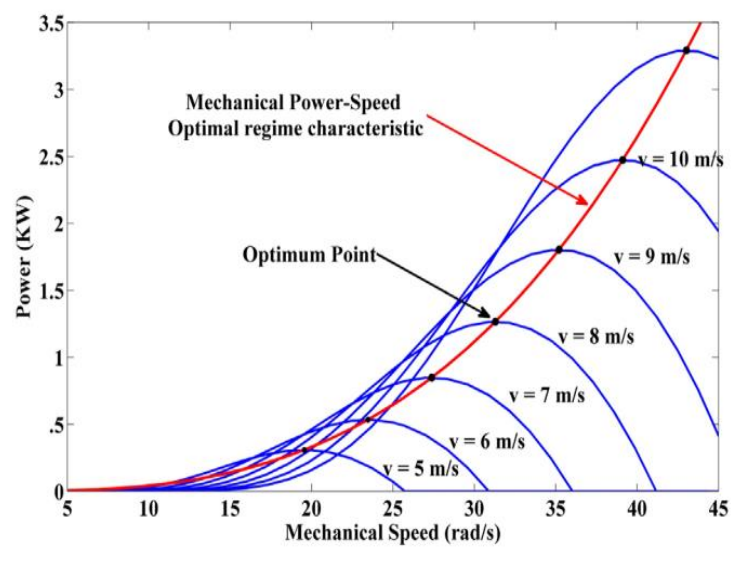

Figure 7. Mechanical power curves at various wind speeds [32]

\section{PROPOSED HCS ALGORITHM TO REACH MPPT}

In this work, three mode algorithms had been combined to be simpler. The adaptive algorithm contains three mode, in it's considered very complicated due to iteration for same equation of $\omega^{*}[8,33]$. Figure 8 shows the novel two mode proposed algorithm. The main aim from the new algorithm is to increase power efficiency, increasing the convergence speed and avoid the trade-off between speed for detection the maximum power point and accuracy of tracking technique. The decision of the algorithm through duty cycle can reach to the curve to maximum peak point due to fewer calculations in the mode stages. The new algorithm is considered simpler than the three modes and faster.

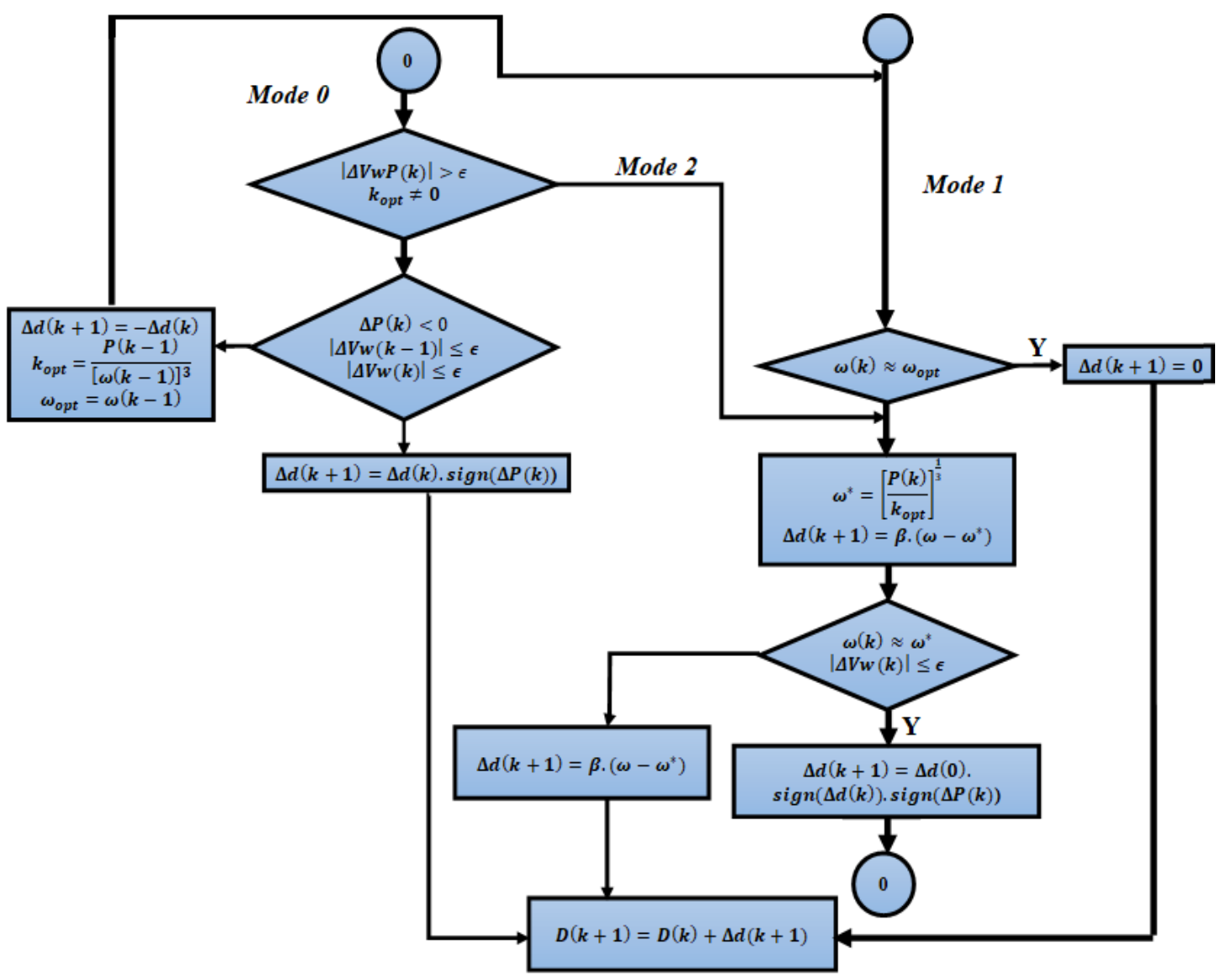

Figure 8. Flowchart of the proposed novel HCS algorithm. 


\section{MODELING THE WECS USING PMSG WIND GENERATORE}

There are five main blocks in the WECS model, which are WT, permanent magnet synchronous generator (PMSG), three phase diode bridge rectifier, controller and DC to DC boost converter. Six wind speed profile effect to the WT as input. Scopes in PMSG measured the stator current, rotor speed, electromagnetic torque and stator voltage. The three-phase output from the PMSG has been rectified using the three-phase diode bridge rectifier.

Figure 9 illustrates the WECS model with three mode HCS algorithm and the proposed HCS algorithm. In this model it can be applied the HCS algorithms to check the efficiency performancefor each algorithm based on the output signal behavior. The scope measurement has been checked the DC voltage via DC link. To enhance the MPPT technique it should be tuning for the model circuit especially DC to DC boost converter. The main function of the controller is to make switching through the duty cycle based on the decision of the algorithm. The three-mode algorithm (Adaptive) makes iterations to reach the MPPT.whereas, the proposed algorithm avoids the iteration delay time to reach the MPPT due to the compined mode as shown in Figure 8.

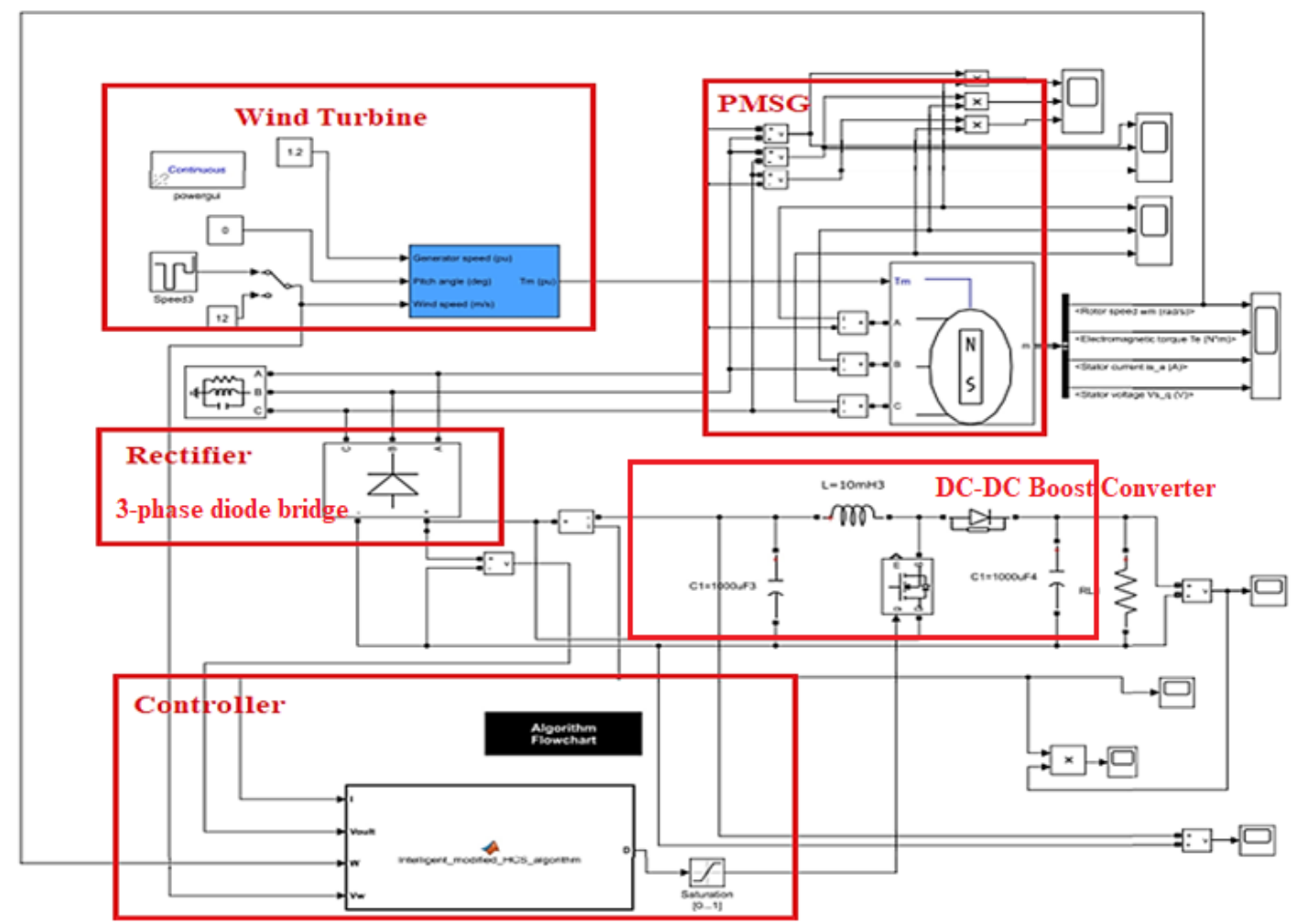

Figure 9. WECS-PMSG model

\subsection{WECS PMSG with three mode algorithm (adaptive)}

In this section, the adaptive or the three-mode algorithm has been applied to the WECS PMSG model using MATLAB SIMULINK. Six wind speed profile the input of the WT. The MATLAB scope measured rotor speed, stator voltage and current, electromagnetic torque and power for PMSG. To enhance the results for the PMSG it should be tuning the parameters to reach to the targeted objective.

In Figure 10 DC voltage had been measured before applying the three-mode algorithm to describe the signal behavior before and after applying the three-mode algorithm, after that the effect of the three-mode algorithm and the proposed algorithm is compared.

Figure 11 shows the DC voltage after applying three mode algorithms. There is a delay to reach the maximum power point because of an iteration processes to reach the MPPT. The three-mode algorithm had tradeoff between efficiency and convergence speed to reach max peak point due to complexity to reach the decision for the peak point. 


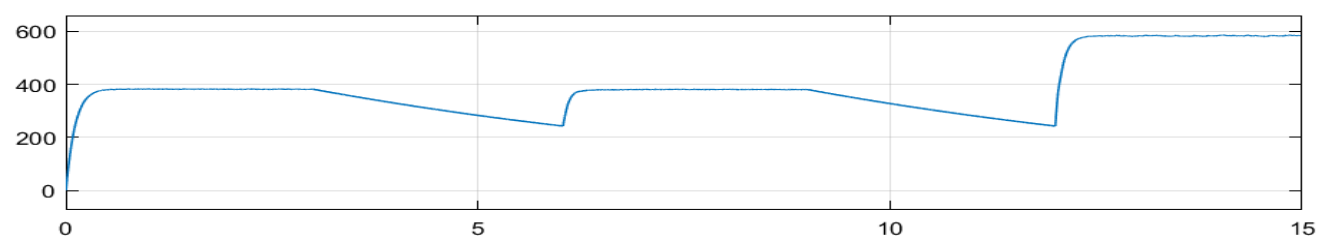

Figure 10. DC voltage before applying the three-mode algorithm

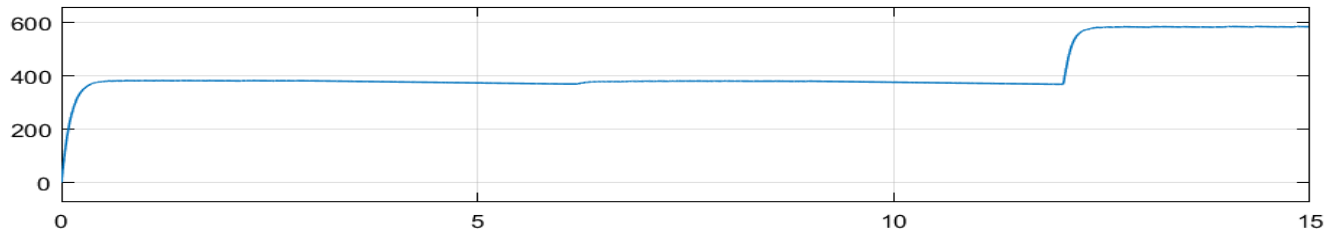

Figure 11. DC voltage after applying HCS three mode algorithm

\subsection{Appling the proposed novel algorithm}

The proposed algorithm has been applied to the WECS. Six wind speed profile the input of the WT to check the efficiency performance for the model under fast varying in wind speed. In Figures 12, 13 it can be seen the three Phase voltage and current are pure sine wave which amplitude increased dramatically direct based on increasing wind speed. Voltage curve and current are in phase, there is no leading or lagging in the phase angle which equals zero. Therefore, the power factor equals 1 . It means that inductive reactance equals to capacitive reactance and that condition called resonance condition.

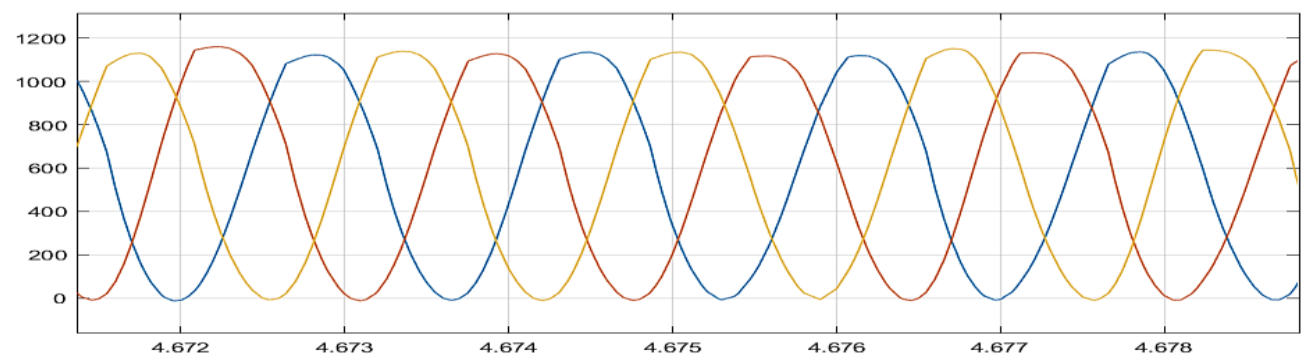

Figure 12 Zoom of generator currents $i_{a b c}$ between $4.672 \mathrm{~s}$ and $4.678 \mathrm{~s}$

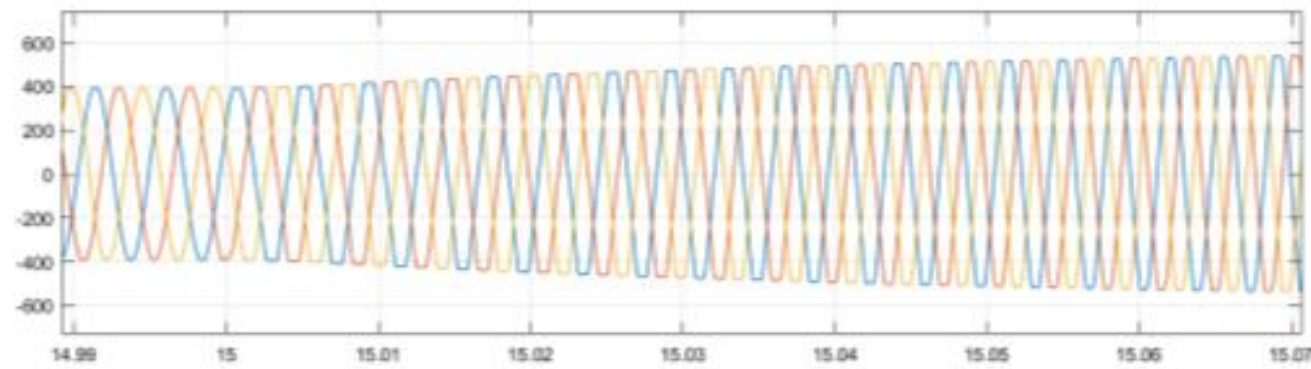

Figure 13. Zoom of generator Voltage $\mathrm{V}_{\mathrm{abc}}$ between $14.99 \mathrm{~s}$ and $15.07 \mathrm{~s}$

The simulation results are shown in pervious figure, the turbine reach to its maximum peak point at a wind speed of $15 \mathrm{~m} / \mathrm{s}$ is applied. The electric power and rotor speed are sampled every 3 seconds after a new rotor reference speed is set. The frequency of the PMSG generator is equal to $50 \mathrm{~Hz}$. 
The new algorithm is controlled in $\mathrm{D}$ duty cycle to control the voltage to reach maximum peak point. Bitch angle is considered constant $(\beta=0)$ irrespective of wind speed. It's clear from Figures 15 and 16 after the rating wind speed the proposed algorithm reached the curve to the maximum point value through the duty cycle. Figure 16 shows the performance of the proposed MPPT algorithm under mixed wind profile with six variation point. The performance of the developed algorithm presents fast tracking capabilities. Moreover, the new technique for HCS can reached to the maximum peak point with minimum calculation which making it simple implementation algorithm and competitive due to summarized three mode to two mode. The proposed algorithm shows fast tracking capability and enhanced stability under both low and high rate of change wind speed conditions and is verified using MATLAB/Simulink.

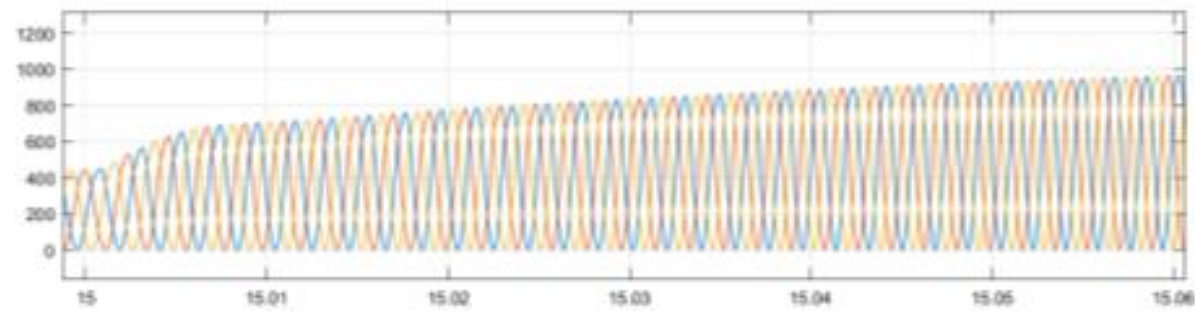

Figure 14. Zoom of generator power output between $15.00 \mathrm{~s}$ and $15.06 \mathrm{~s}$

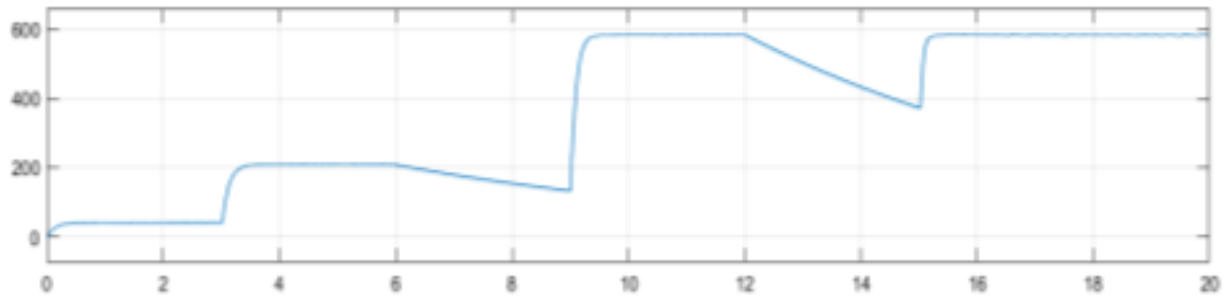

Figure 15. DC voltage before applying two mode algorithms for WECS-PMSG

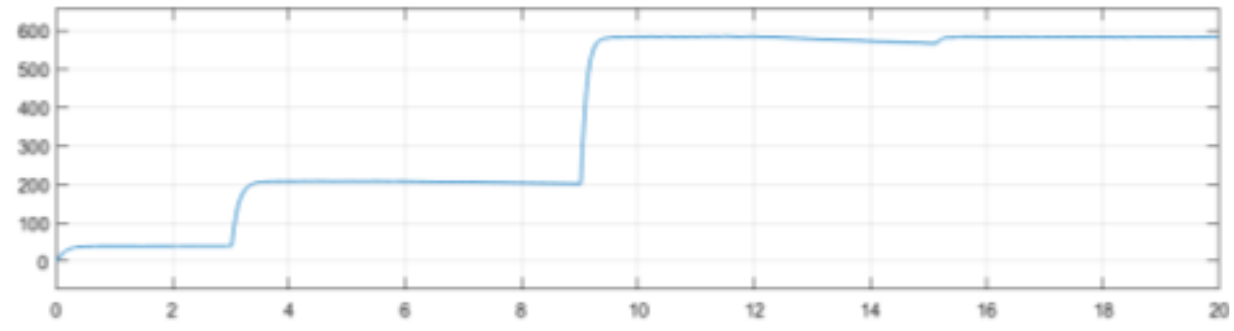

Figure 16. Voltage after applying two mode algorithms for WECS-PMSG

\section{CONCLUSION}

This paper proposed a new technique for HCS algorithm to increase the efficiency performance to reach to the maximum peak point. The proposed algorithm captured the maximum possible power and reached to the maximum power point on the curve at different wind speed without the knowledge of the WT aerodynamic characteristics. The performance of the proposed novel algorithm presents fast tracking capabilities. It can reach to the maximum peak point with minimum calculation which making it simple implementation algorithm and competitive due to summarized three mode to two mode. The experimental results confirm that the proposed technique for HCS is remarkably faster by $20 \%$ of the total time required comparing to the mode algorithm due to simplicity. 


\section{ACKNOWLEDGMENT}

This research has been supported by the research grant no. RIGS16-041-0104 from the Malaysia Ministry of Higher Education in accordance with the Research Initiative Grant Scheme.

\section{REFERENCES}

[1] Simoes, M.G., B.K. Bose, and R.J. Spiegel, "Fuzzy logic based intelligent control of a variable speed cage machine wind generation system," IEEE transactions on power electronics, Vol. 12, no. 1, pp. 87-95, 1997.

[2] Soloumah, H.M. and N.C. Kar, "Fuzzy logic-based vector control of a doubly-fed induction generator in wind power application," Wind Engineering, Vol. 30, no. 3, pp. 201-223, 2006.

[3] Qiao, W., et al., "Wind speed estimation based sensorless output maximization control for a wind turbine driving a DFIG," IEEE transactions on power electronics, Vol. 23, No. 3, pp. 1156-1169, 2008.

[4] Li, H., K. Shi, and P. McLaren, "Neural-network-based sensorless maximum wind energy capture with compensated power coefficient," IEEE transactions on industry applications, Vol. 41, no. 6, pp. 1548-1556.

[5] Buehring, I. and L. Freris. "Control policies for wind-energy conversion systems," in IEE Proceedings CGeneration, Transmission and Distribution, 1981.

[6] Abdullah, M.A., et al., "A review of maximum power point tracking algorithms for wind energy systems," Renewable and sustainable energy reviews, Vol. 16, No. 5 pp. 3220-3227, 2012.

[7] Zhao, Y., et al., "A review on position/speed sensorless control for permanent-magnet synchronous machine-based wind energy conversion systems," IEEE Journal of Emerging and Selected Topics in Power Electronics, Vol. 1, No. 4, pp. 203-216, 2013.

[8] Badawi, A., "Maximum Power Point Tracking Control Scheme for Small Scale Wind Turbine". PhD Thesis 2019.

[9] Badawi, A.S., "An analytical study for establishment of wind farms in palestine to reach the optimum electrical energy," 2013.

[10] Baroudi, J.A., V. Dinavahi, and A.M. Knight, "A review of power converter topologies for wind generators," Renewable energy, Vol. 32, No. 14, pp. 2369-2385, 2007.

[11] Chakraborty, S., B. Kramer, and B. Kroposki, "A review of power electronics interfaces for distributed energy systems towards achieving low-cost modular design," Renewable and Sustainable Energy Reviews, Vol. 13, No. 9, pp. 2323-2335, 2009.

[12] Chen, Z., J.M. Guerrero, and F. Blaabjerg, "A review of the state of the art of power electronics for wind turbines," IEEE Transactions on power electronics, Vol 24, No. 8, pp. 1859-1875, 2009.

[13] Chakraborty, A., "Advancements in power electronics and drives in interface with growing renewable energy resources," Renewable and Sustainable Energy Reviews, Vol. 15, No. 4, pp. 1816-1827, 2011.

[14] Wang, H., et al., "Control and interfacing of a grid-connected small-scale wind turbine generator," IEEE Transactions on Energy Conversion, Vol. 26, No. 2. pp. 428-434, 2011.

[15] Blaabjerg, F. and D.M. Ionel, "Renewable Energy Devices and Systems with Simulations in MATLAB® and ANSYS®". 2017: CRC Press.

[16] Badawi, A., et al., "Evaluation of wind power for electrical energy generation in the mediterranean coast of Palestine for 14 years," International Journal of Electrical and Computer Engineering (IJECE), Vol. 9, No. 4, pp. 2212-2219, 2019.

[17] Kazmi, S.M.R., et al., "A novel algorithm for fast and efficient speed-sensorless maximum power point tracking in wind energy conversion systems", IEEE Transactions on Industrial Electronics, Vol. 58, No. 1, pp. 29-36, 2011.

[18] Abdelsalam, A.K., et al., "High-performance adaptive perturb and observe MPPT technique for photovoltaic-based microgrids," IEEE Transactions on Power Electronics, Vol. 26, No. 4, pp. 1010-1021, 2011.

[19] Abdullah, M.A., et al., "A review of maximum power point tracking algorithms for wind energy systems," Renewable and Sustainable Energy Reviews, Vol. 16, No. 5, pp. 3220-3227, 2012.

[20] 20. Badawi, A., et al., "Resonant Circuit Response for Contactless Energy Transfer under Variable PWM," International Journal of Information and Electronics Engineering, Vol. 7, No. 1, 2017.

[21] Yaseen, E.B., "Renewable energy applications in Palestine", 2009.

[22] Badawi, A.S., et al., "Energy and Power Estimation for Three Different Locations in Palestine," Indonesian Journal of Electrical Engineering and Computer Science, Vol. 5, No. 3, pp. 401-408, 2017.

[23] Badawi, A.S., et al. "Weibull Probability Distribution of Wind Speed for Gaza Strip for 10 Years," Applied Mechanics and Materials. 2019: Trans Tech Publ.

[24] (PCBS), P.C.B.o.S., Wind Speed Data2018.

[25] Badawi, A.S., et al., "Practical electrical energy production to solve the shortage in electricity in palestine and pay back period," International Journal of Electrical and Computer Engineering (IJECE), Vol. 9, No. 6, pp. 46104616, 2019.

[26] Urtasun, A., et al., "Modeling of small wind turbines based on PMSG with diode bridge for sensorless maximum power tracking," Renewable Energy, vol. 55, pp. 138-149, 2013.

[27] Ponkarthik, N. and K. Kalidasa Murugavel, "Performance enhancement of solar photovoltaic system using novel Maximum Power Point Tracking," International Journal of Electrical Power \& Energy Systems, Vol. 60, pp. 1-5, 2014.

[28] Mirbagheri, S.Z., S. Mekhilef, and S.M. Mirhassani, "MPPT with Inc.Cond Method using Conventional Interleaved Boost Converter," Energy Procedia, Vol. 42, pp. 24-32, 2013. 
[29] Thongam, J.S. and M. Ouhrouche, "MPPT control methods in wind energy conversion systems," Fundamental and advanced topics in wind power. 2011.

[30] Dalala, Z.M., et al., "Design and Analysis of an MPPT Technique for Small-Scale Wind Energy Conversion Systems," IEEE Transactions on Energy Conversion, Vol. 28, No. 3, pp. 756-767, 2013.

[31] Heier, S., "Wind Power [a review of Grid Integration of Wind Energy Conversion Systems (S. Heier; 2006); book review]," IEEE Power and Energy Magazine, Vol. 6, No. 3, pp. 95-97, 2008.

[32] Ganjefar, S., A.A. Ghassemi, and M.M. Ahmadi, "Improving efficiency of two-type maximum power point tracking methods of tip-speed ratio and optimum torque in wind turbine system using a quantum neural network," Energy, 2014. 67: p. 444-453.

[33] Badawi, A.S., et al., "Novel HCS Algorithm to reach MPPT for smale scale WECS," Submitted to SN Applied Sciences 2020

\section{BIOGRAPHIES OF AUTHORS}

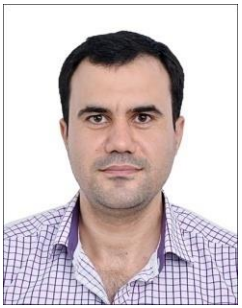

Dr. Ahmed Badawi, has a PhD from International Islamic University Malaysia (IIUM). His study is about maximum power point tracking for small scalewind turbine. Dr. Badawi has a Master degree in Wind Energy, Control Dept. (2013) Islamic University of Gaza, Palestine.Subject: An Analytical Study forEstablishment theWind Farms in Palestine to Reach the OptimumElectrical Energy. Dr. Badawi has recived his B.Sc. Electrical Engineering Communication \& Control Dept. (08th June, 2010) from Islamic UniversityOf Gaza, Gaza, Palestine. Dr. Badawi is a proffesional review in IET and Energy Elsevier International Journal.

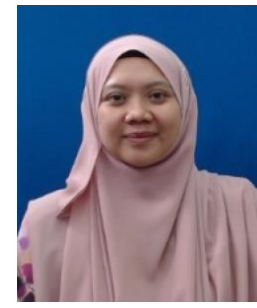

Dr. Nurul Fadzlin Hasbullah is currently an Associate Professor at the Department of Electrical and Computer Engineering, Faculty of Engineering. She graduated with a First Class Honours from Cardiff University, Wales, with a Bachelor of Engineering in 2001. Later, she worked as an Integrated Chip Design Engineer in Malaysia Microelectronics Solution, Cyberjaya for a year before joining academia, teaching at the University Tenaga Nasional (Bangi, Malaysia) as a tutor. In 2003, she moved to International Islamic University Malaysia as an Assistant Lecturer. She obtained her Ph.D from the Un iversity of Sheffield, UK in 2010 researching on the electrical and optical characteristics of quantum dot laser structures. Her research interests continue in the areas of semiconductor device characterization, optical detectors and radiation hard devices.

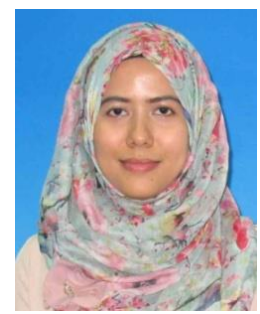

Dr. Siti Hajar Yusoff received the M.Eng. degree in electrical engineering (First Class Honors) and the Ph.D. degree in electrical engineering from University of Nottingham, UK, in 2009 and 2014, respectively. In 2015, she became an Assistant Professor in Department of Electrical and Computer Engineering at International Islamic University Malaysia, Gombak. She is now a lecturer in control of power electronics systems and electrical power system. Her research interests include control of power converters and drives, Matrix, multilevel converters, IoT and renewable energy.

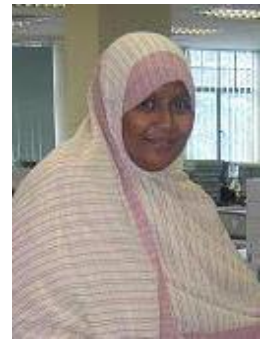

Professor Aisha received her PhD in Computer Engineering (2007), M.Sc. in Computer Science (1996), and B.Sc. in Electronics Engineering (1990). She won the best graduating PhD student Award during the IIUM Convocation ceremony in 2007. She joined IIUM in 1997 and currently working as a Professor at the Department of Electrical and Computer Engineering. Professor Aisha has taught several courses related to Communication and Computer Engineering. She is actively participating in curriculum development and program accreditation. She is a member of theDepartment Board of Studies for several years. She received Best Teacher Award by IIUM duringthe Quality Day in 2007. She has been appointed as external examiner/visiting professor/adjunctprofessor at different universities.

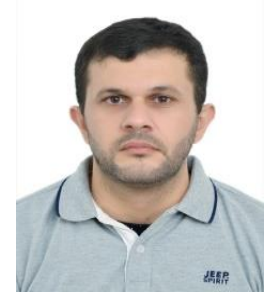

Dr. Alhareth Zyoud received his bachelor degree in electrical engineering from Palestine polytechnic university in 2006, and his master degree in communication engineering from international Islamic University Malaysia (IIUM) in 2011. He got a PhD from IIUM at Electrical and Computer Engineering department. His current research interests are in Interference cancellation, modeling and propagation studies in femtocells $4 \mathrm{G}$ and $5 \mathrm{G}$ networks. $\mathrm{He}$ is a member of the IEEE. 